\title{
IMPACTO AMBIENTAL PROVOCADO PELA DESTINAÇÃO INCORRETA DE PNEUS
}

\section{ENVIRONMENTAL IMPACT CAUSED BY INCORRECT DISCARD OF TIRES}

\section{Recebido: 30/07/2015 - Aprovado: 21/10/2015 - Publicado: 1/12/2015 Processo de Avaliação: Double Blind Review}

Vitória Emanuella da Silva Alves ${ }^{1}$

Doutora em Agronomia pela Universidade Estadual Paulista - UNESP, Botucatu - SP

Professora da Faculdade de Tecnologia e Ciências de Itabuna, BA - FTC

vitoriaemanuella@gmail.com

Guilherme Malta Vasconcelos

Especialista em Gestão de Resíduos Sólidos pela Faculdade de Tecnologia e Ciências de Itabuna, BA - FTC

Engenheiro Ambiental pela Faculdade de Tecnologia e Ciências de Itabuna, BA - FTC

Rafael Nascimento Moreira

Graduando em Engenharia Civil pela Faculdade de Tecnologia e Ciências de Itabuna, BA FTC

Moacir de Jesus Alves Filho

Graduando em Engenharia Civil pela Faculdade de Tecnologia e Ciências de Itabuna, BA FTC

Thassiane da Silva Barreto

Especialista em Gestão de Resíduos Sólidos pela Faculdade de Tecnologia e Ciências de Itabuna, BA - FTC

Engenheira Ambiental pela Faculdade de Tecnologia e Ciências de Itabuna, BA - FTC

\section{RESUMO}

Pneus são resíduos que necessitam de tratamento especial, pois, quando enterrados inteiros, sua forma facilita o acúmulo de gases provenientes da decomposição dos demais resíduos e em caso de afloração à superfície proporciona abrigo para doenças. Deste modo, este trabalho objetivou informar sobre os impactos ambientais provocados pela destinação incorreta de pneus inservíveis também como algumas técnicas de reaproveitamento e reciclagem dos mesmos. Optou-se pela pesquisa bibliográfica, utilizando bancos de dados SCIELO, GOOGLE ACADÊMICO, PERIODICOS CAPES, resoluções do MMA, da ANIP e instruções normativas do IBAMA. O material consultado compreende o espaço temporal de 1992 até 2015, com os seguintes descritores: resíduos industriais; legislações dos

\footnotetext{
${ }^{1}$ Autor para correspondência: Faculdade de Tecnologia e Ciência de Itabaúna, BA- FTC Praça José Bastos, 55 - bairro Osvaldo Cruz - Itabaúna -BA, 45600-080.
} 
pneumáticos; impactos ambientais ocasionados pela disposição final inadequada de pneus e alternativas tecnológicas de pneus servíveis e inservíveis, pois, a destinação inadequada dos pneumáticos inservíveis pode ocasionar impactos negativos como enchentes, por diminuir a capacidade de escoamento de corpos hídricos e bueiros. Em contrapartida, após o uso, o pneu pode passar por processos de reforma e ser reutilizado, mas ao desgastar-se completamente é caracterizado como pneu inservível e a destinação correta são as possíveis maneiras de reciclagem. Assim, é muito importante o cumprimento das legislações que tratam da destinação correta dos pneumáticos.

Palavras-chave: Pneumáticos. Má destinação. Problemas Ambientais.

\begin{abstract}
Tires are wastes that need special treatment, because when buried whole, its shape facilitates the accumulation of gases from the decomposition of other waste and in case of emerge surface provides shelter for diseases. Thus, this research aimed to provide information about the environmental impacts caused by the improper disposal of unserviceable tires and about some techniques for reusing and recycling them. We opted for the literature search using databases SCIELO, GOOGLE SCHOLAR, CAPES journals, resolutions of the MMA, the ANIP and regulations of IBAMA instructions. The consultation material comprises a period from 1992 to 2015 with the following descriptors: industrial waste; laws of tires; environmental impacts caused by improper disposal of tires and technological alternatives usable by tires and scrap therefore improper disposal of scrap tires can cause negative impacts such as floods, by reducing the flow capacity of water bodies and drains. In contrast, after use, the tire can undergo reform and be reused, but the wear out is completely characterized as waste tire and the correct disposal are the possible ways of recycling. Thus it is very important compliance of laws that deal with the proper disposal of tires.
\end{abstract}

Key- words: Improper disposal. Unserviceable tires. Solid wast.

\title{
1. INTRODUÇÃO
}

O avanço tecnológico que visa reduzir a vida útil dos produtos em conjunto com o crescimento populacional ocasionam aumento do consumo e maior geração de resíduos, constituindo um sério problema ambiental, pois a maior parte desses resíduos tem destino final inadequado, comprometendo os recursos naturais.

A geração de resíduos sólidos está relacionada com o crescimento populacional. A expansão desordenada das cidades intensificou os processos industriais e a geração de bens de consumo, além disso, ocasionou comprometimento de áreas adequadas para instalação de aterros sanitários para a destinação final adequada dos resíduos sólidos. 
A ineficiência das políticas públicas que disciplinam e ordena a destinação dos resíduos sólidos e/ou o descompromisso dos geradores no manejo e destinação dos mesmos são algumas das principais causas dos impactos ambientais (LARUCCIA, 2014).

Desde a publicação da Lei 12.305/2010 - Política Nacional de Resíduos Sólidos novas prioridades foram incorporadas ao sistema de gestão e gerenciamento de resíduos sólidos, cabendo às administrações públicas municipais, a prática de um conjunto de instrumentos e ações de gestão integrada e ao gerenciamento ambientalmente adequado dos resíduos sólidos.

O gerenciamento correto dos resíduos sólidos no Brasil representa um dos grandes desafios enfrentados pelos municípios. Esse problema ocorre por conta dos aspectos sanitários e ambientais envolvidos no que tange à operacionalização do Sistema de Limpeza Urbana, devido às quantidades geradas, associadas, entre outras razões, às características dos materiais.

A Associação Brasileira de Normas Técnicas - ABNT (2004) NBR 10.004 define que resíduos nos estados sólidos ou semissólidos são gerados a partir de atividades de origem industrial, doméstica, hospitalar, comercial, agrícola, de serviços e de varrição. Assim, os pneus inservíveis são classificados como: classe II B - resíduo inerte, por não ser solúvel em água. Apesar de ser um material inerte, o pneu precisa de uma destinação final especial.

De acordo com IBGE (2014), o Brasil possui cerca de 202,7 milhões de habitantes e 86,7 milhões de veículos registrados (DENATRAN, 2014). Assim, o Brasil possui uma média de 2,3 habitantes/veículos. Segundo projeções realizados pela Empresa de Pesquisa Energética (EPE, 2014), estima-se que a frota de veículos individuais e comerciais leves irá atingir cerca de 130 milhões de unidades até 2050, isto é aproximadamente 1 veículo a cada 1,7 habitantes.

Portanto, este produto começa a ocupar papel de destaque na discussão dos impactos sanitários e ambientais. Quando descartados incorretamente contribuem com a degradação da natureza e a proliferação de vetores de doenças como a dengue e a febre amarela, também ao serem deixados em rios e córregos podem aumentar a velocidade de escoamento em função da redução da seção. O pneu não se decompõe naturalmente, quando depositado em aterros, as camadas de ar fazem com que aflore à superfície. Ao ser queimado, libera gases poluentes.

A logística de planejamento, controle, estocagem e transporte do material pós-venda e pós-consumo agregando-lhe valores econômicos e ecológicos é denominada de logística reversa, pois se trata do fluxo inverso no ciclo produtivo, partindo do ponto de consumo em direção ao ponto de origem (SOUZA, 2014).

No Brasil, a logística reversa é regulamentada pelo Conselho Nacional de Meio Ambienta (CONAMA). Na resolução $n^{\circ} 258$ de 1999 do CONAMA, o governo federal determina que fabricantes e importadores recolham e deem um fim ambientalmente adequado aos pneus que comercializam no país. Dez anos depois, no ano de 2009, a resolução citada acima deu lugar à resolução CONAMA (2009) n n 416, onde além das determinações da antecessora, fica explícito que os pneus usados devem ser preferencialmente reutilizados ou reformados e sua destinação final adequada é a reciclagem (BRASIL, 1999; 2009). 
Para um destino adequado, entende-se o reaproveitamento dos pneus nas variadas formas possíveis. Os processos de reforma para reutilização dos pneus consistem basicamente em 3 (três) métodos: recapagem, recauchutagem e remoldagem. A reciclagem se aplica quando o pneu é considerado inservível e pode se dar das seguintes maneiras: pirólise genérica, asfalto borracha, coprocessamento, bloco de concreto utilizando resíduo de borracha, na recuperação de áreas erodidas e artefatos e artesanatos de borracha entre outras.

Hoje, por conta da grande preocupação com a saúde pública e o meio ambiente, o Brasil tem apresentado políticas nos âmbitos federal, estadual e municipal para a destinação dos pneumáticos e coibir a importação de pneus usados principalmente do continente europeu. É notado também que algumas empresas já demonstram atitudes mais sustentáveis, assumindo a responsabilidade pela destinação final adequada de pneus e se enquadrando aos parâmetros legais. Devido a essas problemáticas objetivou-se informar sobre os impactos ambientais provocados pela destinação incorreta de pneus inservíveis e a respeito de algumas técnicas de reaproveitamento e reciclagem.

\section{REFERENCIAL TEÓRICO}

\subsection{COMPOSIÇÃO DO PNEU}

O principal componente do pneu é a borracha, representando $41 \%$ do peso total, podendo ser classificada em borracha natural e borracha sintética. A natural é obtida através da seiva da planta hevea brasiliensis, mais conhecida como seringueira. Já a sintética é derivada do petróleo ou do gás natural. No Brasil mais de $50 \%$ da borracha consumida é destinada a fabricação de pneus (BNDES, 1998).

As outras matérias primas utilizadas são: o negro de fumo (derivado do petróleo), arame de aço, fibras orgânicas (nylon e poliéster) e outros produtos químicos (BNDES, 1998). A tabela 1 a seguir representa a composição química dos pneus e a tabela 2 os materiais componentes e o percentual de cada.

Tabela 1 - Composição química dos pneus.

\begin{tabular}{cc}
\hline Componente Químico & Percentual \\
\hline Carbono & $83 \%$ \\
Oxigênio & $7 \%$ \\
Cinzas & $6 \%$ \\
Hidrogênio & $2,5 \%$ \\
Enxofre & $1,2 \%$ \\
Nitrogênio & $0,3 \%$
\end{tabular}

Fonte: Ramos, 2005. 
Tabela 2 - Composição dos pneus.

\begin{tabular}{cc}
\hline Componente & Percentual \\
\hline Negro de Fumo & $28 \%$ \\
\hline Borracha Sintética & $27 \%$ \\
\hline Borracha Natural & $14 \%$ \\
\hline Arame de Aço & $10 \%$ \\
\hline Extender Oil & $10 \%$ \\
\hline Produtos Químicos & $7 \%$ \\
\hline Fibras Orgânicas & $4 \%$ \\
\hline
\end{tabular}

Fonte: BNDES, 1998.

\subsection{TÉCNICAS DE REAPROVEITAMENTO E RECICLAGEM DE PNEUS}

Conforme Parra, Nascimento e Ferreira (2010), o pneu se faz um produto de suma importância para a sociedade, mas o fato é que desde sua geração representa um problema ambiental. Próximo ao fim da sua vida útil, o pneu ainda pode passar por processos de reforma e ser reutilizado, mas ao desgastar-se completamente é caracterizado como pneu inservível e a destinação correta são as possíveis maneiras de reciclagem.

No Quadro 1 a seguir são apresentadas as definições dos processos de recapagem, recauchutagem e remoldagem, considerados como reforma de pneus, em concordância com a resolução CONAMA nº 416 de 2009.

Quadro 1 - Definição dos processos de recapagem, recauchutagem e remoldagem.

\begin{tabular}{|l|l|l|}
\hline \multicolumn{1}{|c|}{ Recapagem } & \multicolumn{1}{|c|}{ Recauchutagem } & \multicolumn{1}{c|}{ Remoldagem } \\
\hline Processo pelo qual um pneu & Processo pelo qual um pneu & Processo pelo qual um pneu \\
usado é reformado pela & usado é reformado pela & usado é reformado pela \\
substituição de sua banda de & substituição de sua banda de & substituição de sua banda \\
rodagem. & rodagem e dos ombros. & \begin{tabular}{l} 
a superfície de seus flancos. \\
\hline
\end{tabular}
\end{tabular}

Fonte: BRASIL, 2009. 
O impacto ambiental do processo de recauchutagem do pneu é muito menor do que o impacto da produção de um pneu novo. A menor quantidade de matéria prima necessária para a recauchutagem implica na redução de até $80 \%$ no custo do processo (CONSTANTINESCU, 2012).

Para os processos de reciclagem, explica-se: de acordo com Lagarinhos e Tenório (2009) a pirólise genérica é um processo em que se obtêm os compostos orgânicos do pneu através de degradação térmica e falta de oxigênio. Nesse tipo de reciclagem é reaproveitado uma margem de $90 \%$ do pneu inservível. Os principais resultados da decomposição química são: óleo negro (utilizado como combustível), negro de fumo (para indústria de borracha) e o aço (para a indústria siderúrgica).

Segundo Tchobanoglous, Theisen e Eliassen (1993) apud Cimino (2004) a incorporação da borracha ao asfalto pode se dar em dois processos. No processo seco, a borracha triturada é utilizada em substituição do agregado, formando um produto denominado concreto asfáltico modificado com adição de borracha. O outro processo é o úmido, no qual a borracha triturada é incorporada ao asfalto a uma temperatura de $204{ }^{\circ} \mathrm{C}$, resultando em uma liga química, denominada asfalto borracha.

Conforme Mattioli, Monteiro e Ferreira (2009) por conta de seu elevado poder calorífico, o pneu pode ser utilizado como combustível em fornos de clínquer nas indústrias de cimento. Esse processo é regulamentado pela resolução CONAMA 264/99. Os autores também afirmam que estão sendo realizadas experiências bem sucedidas na área da construção civil que é a adição de resíduos de borracha nos blocos de concreto. Os blocos são de uso não estrutural, mas ensaios de laboratório podem garantir esse uso, desde que atendam aos parâmetros estabelecidos pela NBR 7184/1992.

Na recuperação de áreas degradadas, Parra, Nascimento e Ferreira (2010) afirmam que nesse método, os pneus inservíveis podem ser enterrados em solos com grandes erosões (voçorocas) ou utilizados para construir barreiras de assoreamento como parte estratégica na recuperação de áreas erodidas. Artesanato e artefatos de borracha são cada vez mais produzidos e ganhando incentivo no Brasil. Além de colaborar com o meio ambiente, a reciclagem de pneus inservíveis através da arte, gera renda e promove a inclusão social sendo de fato uma atividade sustentável.

\section{METODOLOGIA}

A pesquisa bibliográfica pode ser entendida como o ato de indagar e de buscar informações sobre determinado assunto, através de um levantamento realizado em base de dados nacionais e estrangeiros. De acordo com Lakatos e Marconi (1992), o levantamento bibliográfico é caracterizado como pesquisa de fontes secundárias, pois se trata de um levantamento de bibliografia já publicada em formas de livros, revistas, publicações avulsas e imprensa escrita. Dessa forma, o presente trabalho utiliza o referencial da pesquisa bibliográfica a respeito de impactos ambientais provenientes da destinação incorreta de pneus inservíveis.

Com este propósito foi efetuada uma revisão das publicações na área ambiental, tendo sido consultadas as bases de dados Scielo, Google e Periódicos Capes, bem como 
informações e resoluções disponíveis no site do Ministério do Meio Ambiente, da Associação Nacional da Indústria de Pneumáticos e instruções normativas consultadas no site do Instituto Brasileiro do Meio Ambiente e dos Recursos Naturais Renováveis.

Foram utilizados como critérios de inclusão os textos que explanavam a respeito da problemática dos pneus e do seu destino final, publicados entre 1992 e 2015. Assim, foram excluídos aqueles que não atendiam aos critérios.

Os artigos selecionados foram organizados em tópicos e sintetizados para análise. Os descritores investigados serão concernentes a: Classificação dos resíduos industriais; Legislação sobre pneumáticos; Impactos ambientais ocasionados pela disposição final inadequada dos pneus; Alternativas tecnológicas de pneus servíveis e inservíveis.

\section{RESULTADOS E DISCUSSÃO}

Juntamente com o surgimento do pneu e sua fabricação em massa, vieram os problemas ambientais e de saúde pública por conta da má destinação após a utilização do produto. A produção mundial de pneus gira em torno de um bilhão de unidades por ano o que justifica Scagliuse (2011) afirmando que esse número se dá por conta da demanda do mercado de reposição e das montadoras de automóveis, pois para cada veículo novo necessita-se de cinco pneus novos.

Conforme Andrade (2007) para pneus de passeio a demanda mundial é de $60 \%$ para o mercado de reposição e $40 \%$ para as montadoras. Já se tratando de pneus para caminhões e ônibus, 85\% da produção para reposição e apenas 15\% para as montadoras. Scagliuse (2011) faz defesa aos números apresentados, afirmando que o segmento de reposição absorve maior quantidade, pois houve um declínio na produção mundial de veículos.

Lagarinhos (2011) afirma que as fábricas de pneumáticos instaladas no Brasil, garantem ao país a $7^{\mathrm{a}}$ colocação no âmbito mundial para pneus de passeio e a $5^{\mathrm{a}}$ colocação para pneus de caminhões, ônibus e camioneta. A região sudeste é onde se encontra o maior número de multinacionais instaladas. Só no estado de São Paulo estão localizadas 8 empresas das 17 instaladas em todo o país.

A produção brasileira é distribuída da seguinte maneira: exportação, demanda do mercado das montadoras de veículos novos e à substituição de pneus antigos. Goldenstein, et al., (2007) afirma que as montadoras respondem por $26 \%$ das vendas, o mercado de reposição por $42 \%$ e os $32 \%$ restante destinados a exportação, sendo comercializado com cerca de cem países, os principais são Estados Unidos, França, Argentina e México.

Desde 1998, as indústrias de pneus já se mostravam preocupadas com as questões ambientais, portanto ocorreram inovações no setor proporcionando economia de até $4 \%$ de combustível, ou seja, menor emissão de gases (BNDES 1998). A ANIP afirma que mesmo algumas indústrias demonstrando preocupação com a reciclagem dos pneus, o CONAMA, em 1998, iniciou estudos com o intuito de implantar a reciclagem de pneus (ARNALDI, 2003).

Desde a última resolução do CONAMA para pneumáticos (resolução $n^{0} 416$ de setembro de 2009), o IBAMA tem divulgado anualmente relatório de pneumáticos, almejando 
declarar números referentes ao cumprimento da legislação em vigor. Até hoje, foram divulgados 4 relatórios anuais a partir 2011, sendo que as informações contidas nos relatórios são referentes ao ano anterior.

O primeiro relatório abrange maior espaço de tempo, pois compreende os períodos do último trimestre de 2009 até dezembro de 2010. Nele foram analisadas informações consolidadas de 15 empresas fabricantes e 466 importadoras. Para o segundo relatório foram analisadas informações de 17 empresas fabricantes e 436 importadoras. No terceiro relatório foram analisadas informações de 17 empresas fabricantes e 604 importadoras. No último relatório divulgado, referente ao ano de 2013, os dados consolidados analisaram informações de 18 empresas fabricantes e 623 importadoras. Os números dos quatro relatórios estão descritos na tabela 3 a seguir.

Tabela 3 - Meta e saldo de pneus destinados desde 2009.

\begin{tabular}{ccccc}
\hline PERÍODO & $\mathbf{2 0 0 9 - 2 0 1 0}$ & $\mathbf{2 0 1 1}$ & $\mathbf{2 0 1 2}$ & $\mathbf{2 0 1 3}$ \\
\hline Meta para destinação (em t.) & $560.337,64$ & $545.810,67$ & $479.429,60$ & $535.267,80$ \\
Saldo destinação (em t.) & 555.107 .62 & $462.457,19$ & $459.030,18$ & $491.653,02$ \\
Déficit da destinação (em t.) & $5.230,02$ & $83.353,48$ & $20.399,42$ & $43.614,78$ \\
Déficit da destinação \% & 0,94 & 15,27 & 4,25 & 8,14 \\
\hline Fonte: BRASIL, 2011; 2012a; 2013; 2014a. & & & &
\end{tabular}

Fazendo um comparativo entre os dados da tabela acima, percebe-se que em 2011, o déficit na destinação dos pneus inservíveis apresenta um número aproximadamente 16 vezes maior que o déficit do período anterior. Dessa forma, no final de 2009 e ano de 2010, foram destinados 99\% dos pneumáticos e em 2011 o percentual reduziu para 84,73\%. Já em relação aos dados do ano de 2012, pode-se perceber que o déficit apresenta números melhores que o ano anterior, sendo 95,75\% da meta para a destinação atingida. Porém no ano de 2013 a destinação foi menor, com quase o dobro do déficit do ano anterior foram destinados $91,86 \%$.

As metas globais de destinação são obrigações a serem cumpridas por fabricantes e importadores, como está explícito na legislação, por isso, o IBAMA dividiu as metas de cada parte. A tabela 4, a seguir, apresenta as quantidades que deveriam ser destinadas corretamente e o valor real que teve destino correto do final de 2009 até dezembro de 2013.

Tabela 4 - Meta e destinação dadas pelos fabricantes e importadores desde outubro de 2009 a dezembro de 2013.

\begin{tabular}{ccccc}
\hline PERÍODO & 2009-2010 & 2011 & 2012 & 2013 \\
\hline Meta fabricantes (em t.) & $357.743,12$ & $280.119,09$ & $301.152,88$ & $352.756,79$ \\
Destinação fabricantes (em t.) & $378.774,09$ & $285.138,58$ & $317.150,53$ & $377.212,84$ \\
Cumprimento fabricantes \% & 105,78 & 101,79 & 105,31 & 106,93 \\
\hline
\end{tabular}




\begin{tabular}{ccccc}
\hline Meta Importadores (em t.) & $202.594,52$ & $265.691,58$ & $178.276,72$ & $182.511,01$ \\
Destinação Importadores (em t.) & $176.333,53$ & $177.318,61$ & $141.879,66$ & $114.440,18$ \\
Cumprimento importadores \% & 87,04 & 66,74 & 79,58 & 62,70 \\
\hline
\end{tabular}

Fonte: BRASIL, 2011; 2012a; 2013; 2014a.

Ao interpretar os dados da tabela acima, percebe-se que os fabricantes têm superado as metas em todos os anos, sendo que no período de 2009-2010 o cumprimento da meta atingiu $105,88 \%$. Os importadores não conseguiram atingir 100\% da meta em nenhum dos períodos. O ano mais crítico foi 2013, quando os importadores atingiram apenas 62,70\% da obrigação. É curioso que a quantidade a ser destinada em 2009-2010 era maior que nos demais períodos, e o cumprimento das empresas apresentaram melhores resultados.

A Associação Nacional das Indústrias de Pneumáticos - ANIP é uma associação de 11 marcas fabricantes de pneus instaladas no Brasil, porém em 2012, o número de empresas que fabricam pneumáticos que são cadastradas no IBAMA, era de 17 empresas (entre sedes e filiais). De acordo com informações da ANIP, referente ao ano de 2014, a produção foi de 68,7 milhões de unidades de pneus (ANIP, 2015).

A quantidade de pneus que ainda não são destinados corretamente representa grande risco de contaminação ambiental. O pneu é um produto que tem poder calorífico bastante elevado, e o maior dano ambiental que pode causar é quando ocorre a queima descontrolada (induzida ou acidental) a céu aberto.

Ao entrar em combustão em área aberta, o pneu libera gases que contém substâncias tóxicas como monóxido de carbono (CO), óxido de enxofre (SOx), óxido de nitrogênio (NOx) e compostos orgânicos voláteis, além de dioxinas, furanos, ácido clorídrico e benzeno. Todos esses compostos químicos sem tratamento e em meio atmosférico afetam de forma agressiva a qualidade do ar (SILVA; PACHECO, 2004).

Lagarinhos e Tenório (2008) consideram que os maiores riscos de contaminação ambiental na queima de pneus são os subprodutos: óleo pirolítico e as cinzas. Por conta da diminuição do oxigênio do ar e das altas temperaturas, ocorrem reações de pirólise, produzindo o óleo pirolítico e nas cinzas ocorre a presença de metais pesados.

Ainda em conformidade aos autores citados acima, a água utilizada no combate aos incêndios em grande número de pneus aumenta a produção de óleo pirolítico e serve como meio eficaz para o seu transporte e contaminação do solo e de águas superficiais e subterrâneas.

O principal impacto sanitário ocasionado pela má destinação dos pneus é a proliferação de vetores de patógenos ao ser humano e em especial à dengue. Essa é uma doença endêmica no Brasil e a proliferação do mosquito que a transmite (Aedes aegypti) se faz em locais que acumulam água parada, dessa forma, pneus mal acondicionados servem como berçário perfeito para multiplicação dos transmissores. 
De acordo com dados do Ministério da Saúde (2012) referente ao estudo feito entre Janeiro e Abril de 2011 e 2012, houve uma diminuição de 507.798 casos de dengue nesse período de 2011 para 286.011 casos no mesmo período de 2012, a partir do aumento da contribuição da destinação final dos pneus inservíveis que passou de 84,73\% para 95,75\%. Porém, com base nos dados divulgados pelo Ministério da Saúde (2014) referente ao ano de 2013, houve um grande aumento nos casos de dengue registrados em relação ao ano anterior, uma queda de 3,89\% na taxa de destinação final dos pneus inservíveis contribuiu para um salto de 286.011 no primeiro trimestre de 2012 para 1.111 .003 no mesmo período de 2013 (BRASIL, 2012b; BRASIL, 2014b).

As técnicas de reforma representam uma série de vantagens comparadas à produção de pneumáticos novos. A recapagem e recauchutagem utilizam apenas $25 \%$ do material necessário para fabricação de um pneu novo, garantem bom desempenho com custo $70 \%$ menor, a mesma carcaça pode ter até 3 vidas e economia de 57 litros de petróleo por pneu reformado. Algumas vantagens da remoldagem são: resistência ao movimento 3\% maior que pneus novos, utilizam 25 vezes menos água, custo de 30 a 50\% menor, economia de 20 a 40 litros de petróleo e consumo de energia 2,3 vezes menor (LAGARINHOS; TENÓRIO, 2008).

Nas perspectivas dos marcos legais referentes à destinação final ambientalmente adequada dos pneumáticos inservíveis, e embasada por informações dos Relatórios de Pneumáticos do IBAMA referentes aos espaços temporais de outubro de 2009 a dezembro de 2010, ano de 2011 e 2012, a tabela 5 mostra as destinações dadas por fabricantes e importadores de pneus.

Tabela 5 - Destinação dada aos pneus inservíveis por fabricantes e importadores.

\begin{tabular}{|c|c|c|c|c|c|c|c|c|}
\hline \multirow[t]{2}{*}{ PERÍODO } & \multicolumn{2}{|c|}{ 2009-2010 } & \multicolumn{2}{|c|}{2011} & \multicolumn{2}{|l|}{2012} & \multicolumn{2}{|c|}{2013} \\
\hline & $\begin{array}{c}\text { Qtd. } \\
\text { Destinada } \\
\text { (t.) }\end{array}$ & $\%$ & $\begin{array}{c}\text { Qtd. } \\
\text { Destinada } \\
\text { (t.) }\end{array}$ & $\%$ & $\begin{array}{c}\text { Qtd. } \\
\text { Destinada } \\
\text { (t.) }\end{array}$ & $\%$ & $\begin{array}{c}\text { Qtd. } \\
\text { Destinad } \\
\text { a (t.) }\end{array}$ & $\%$ \\
\hline Coprocessame & 294.956,9 & 53,1 & 256.481,2 & 55,4 & 219.269,0 & 47,7 & 267.448, & 54,4 \\
\hline nto & 4 & 4 & 4 & 6 & 9 & 7 & 35 & 0 \\
\hline \multirow[t]{2}{*}{ Granulação } & 160.768, & 28,9 & 138.313, & 29,9 & 168.499, & 36,7 & 165.574, & 33,6 \\
\hline & 18 & 6 & 28 & 1 & 14 & 1 & 82 & 8 \\
\hline \multirow[t]{2}{*}{ Laminadora } & $91.714,7$ & 16,5 & $59.197,8$ & 12,8 & $61.115,9$ & 13,3 & $43.839,4$ & 8,92 \\
\hline & 0 & 2 & 8 & 0 & 3 & 1 & 4 & \\
\hline Industrializaç & $7.549,51$ & 1,36 & $8.334,18$ & 1,80 & $9.810,00$ & 2,14 & $14.700,0$ & 2,99 \\
\hline ão do xisto & & & & & & & 0 & \\
\hline
\end{tabular}




\begin{tabular}{ccccccccc}
\hline Outras & 118,28 & 0,02 & 130,65 & 0,03 & 336,03 & 0,07 & 90,41 & 0,01 \\
\hline
\end{tabular}

Fonte: BRASIL, 2011; 2012a; 2013; 2014a.

A partir da tabela apresentada acima, percebe-se que o principal destino dado ao pneu é o coprocessamento que é a utilização dos pneus inservíveis em fornos de clínquer como substituto parcial de combustíveis e como fonte de elementos metálicos. O que justifica esses números é a grande quantidade de pneus que o processo demanda aliada a algumas vantagens tais como: alto poder calorífico do pneu, diminuição dos custos com energia, possui liberação legal, substitui combustíveis fósseis, gera menos emissões que o carvão e não produz resíduo (CIMINO 2004; KAMIMURA, 2002 apud ANDRADE, 2007).

\section{CONSIDERAÇÕES FINAIS}

A partir do levantamento bibliográfico desta pesquisa, evidenciou o pneu é um produto muito presente para a sociedade como um todo e quando considerado inservível pode representar grande ameaça a qualidade do meio ambiente e da saúde pública quando mal destinado. Diante disso, é muito importante o cumprimento das legislações que tratam da destinação correta dos pneumáticos.

A responsabilidade pela coleta e destinação dos pneus foi atribuída aos fabricantes e importadores. O interessante é que a cada ano o percentual de destinação apresente evolução, pois uma pequena porcentagem de pneus não destinados é preocupante, levando em considera a larga escala de produção anual.

Além disso, o pneu pode colaborar para proliferação da dengue, uma doença responsável por um alto índice de mortalidade da população brasileira. Os produtos da queima incontrolada são ameaça para o meio e para saúde humana, então não se pode regredir nos percentuais de destinação e sim cumpri-los ou quem sabe até superá-los. Dessa forma os importadores de pneus deveriam mirar-se no exemplo dados pelos produtores, pois estes nos dois últimos anos têm superado a meta, se mantendo dentro dos padrões da lei.

As alternativas para os processos de reforma dos pneus são apresentadas com grandes vantagens econômicas e ecológicas em relação à produção de novos produtos. Pôde-se observar também que dentro dos processos de reciclagem o coprocessamento tem se destacado, pois é grande a quantidade de pneu inservível e este apresenta características bastante favoráveis para servir como matéria prima.

Portanto, a ideia de passivo ambiental atribuída ao pneu depende muito do gerenciamento dado a este produto ao fim de sua vida útil. A coleta e destino do pneumático inutilizado para sua função principal é obrigatoriedade das empresas fabricantes e importadores, mas é válido ressaltar que é de extrema importância à mudança de hábito da população na destinação do pneu, pois esse produto pode apresentar uma gama de vantagens econômicas e ambientais quando envolvido em outros processos. 


\section{REFERÊNCIAS}

ANDRADE, H.. S. Pneus inservíveis: Alternativas possíveis de reutilização. 2007. $101 \mathrm{f}$. Trabalho de Conclusão de Curso (Graduação em Ciências Econômicas) - Universidade Federal de Santa Catarina, Florianópolis, 2007.

ARNALDI, J. C.. Reciclagem de pneus: desafios e tendência. In: SEMINÁRIO: RECLICAGEM DE MATERIAIS DESAFIOS E TENDÊNCIA, 2003, São Paulo. Anais... São Paulo: AEA, 2003.

ASSOCIAÇÃO NACIONAL DAS INDÚSTRIAS DE PNEUMÁTICOS - ANIP. Disponível em: <http://www.anip.com.br> Acesso em: 25 de jul. 2015.

ASSOCIAÇÃO BRASILEIRA DE NORMAS TÉCNICAS - ABNT. Resíduos sólidos: classificação. NBR 10004. Rio de Janeiro, 2004.

BANCO NACIONAL DE DESENVOLVIMENTO ECONÔMICO E SOCIAL - BNDES.

Pneus. Brasília, 1998. Disponível em:<//www.bndes.gov.br/conhecimento/relato/pneus.pdf $>$. Acesso em: 07 de mai. 2013.

BRASIL. Conselho Nacional de Meio Ambiente - CONAMA. Resolução CONAMA n. 416, de 30 de Setembro de 2009. Diário Oficial da União, Brasília, 01 out. 2009 . p. 64-65. Disponível em: <http://www.mma.gov.br/port/conama/legiabre.cfm?codlegi=616> . Acesso em: 25 jun. 2015.

BRASIL. Conselho Nacional de Meio Ambiente - CONAMA. Resolução CONAMA n. 258, de 26 de Agosto de 1999. Diário Oficial da União, Brasília, 02 dez. 1999. Seção 1, p. 39. Disponível em: <http://www.mma.gov.br/port/conama/legiabre.cfm?codlegi=258> . Acesso em 10 jul. 2015.

BRASIL. Instituto Brasileiro do Meio Ambiente e dos Recursos Naturais Renováveis IBAMA. Relatório de pneumáticos, 2014a. Disponível em:

< http://www.ibama.gov.br/phocadownload/category/4?download=9649\%3Arelatoriopneumaticos-2014>. Acesso em: 20 de jul. 2015.

BRASIL. Instituto Brasileiro do Meio Ambiente e dos Recursos Naturais Renováveis IBAMA. Relatório de pneumáticos, 2013. Disponível em:

$<$ http://www.ibama.gov.br/phocadownload/category/4?download=7487\%3Arelatorio_pneum atico_2013>. Acesso em: 20 de jul. 2015.

BRASIL. Instituto Brasileiro do Meio Ambiente e dos Recursos Naturais Renováveis IBAMA. Relatório de pneumáticos, 2012a. Disponível em:<http://www.ibama.gov.br/phocadownload/category/4?download=5702\%3Arelatriopneumticos-2012>. Acesso em: 05 de mai. 2013.

BRASIL. Instituto Brasileiro do Meio Ambiente e dos Recursos Naturais Renováveis IBAMA. Relatório de pneumáticos, 2011. Disponível em: 
<http://www.ibama.gov.br/phocadownload/category/4?download=3925\%3Arelatriopneumticos-2011>. Acesso em: 05 de mai. 2013.

BRASIL. Secretaria de Vigilância em Saúde do Ministério da Saúde. Boletim Epidemiológico - Dengue: monitoramento até a semana epidemiológica (SE), 2014b.

Disponível em: < http://portalsaude.saude.gov.br/images/pdf/2014/maio/29/BE-2014-45--5-semana-16.pdf $>$. Acesso em: 23 de mai. 2015.

BRASIL. Secretaria de Vigilância em Saúde do Ministério da Saúde. Boletim Epidemiológico - Dengue: situação epidemiológica, 2012b. Disponível em: <http://portalsaude.saude.gov.br/images/pdf/2014/julho/23/BE-2012-43--1--pag-11-a-15Dengue.pdf > . Acesso em: 23 de mai. 2015.

CIMINO, M. A. Gerenciamento de pneumáticos inservíveis: análise crítica de procedimentos operacionais e tecnologias para minimização, adotados no território nacional. 2004. $192 \mathrm{f}$. Dissertação (Mestrado em Engenharia Urbana) - Universidade Federal de São Carlos UFSCAR, São Carlos, 2004.

CONSTANTINESCU, Constantin. Ecological Dimension of Tire Management. Environmental Impact of tire use. International Journal of Academic Research in Accounting, Bucharest, v. 2, n. 1, p. 187-195, out. 2012.

DEPARTAMENTO NACIONAL DE TRÂNSITO - DENATRAN. Frota 2014. Brasília, 2014. Disponível em: <http://www.denatran.gov.br/frota>. Acesso em: 26 de jul. 2015.

EMPRESA DE PESQUISA ENERGÉTICA - EPE. Nota Técnica DEA 13/14. Demanda de Energia 2050. Empresa de Pesquisa Energética, Rio de Janeiro, Brasil. 245 pp. Disponível em:

$<$ http://www.epe.gov.br/Estudos/Documents/PNE2050_Premissas\%20econ\%C3\%B4micas\% 20de\%20longo\%20prazo\%20v2\%20(31032015).pdf>. Acesso em: 25 de jul. 2015.

GOLDENSTEIN, M.; ALVES, M. F.; BARRIOS, M. T.. Panorama da indústria de pneus no Brasil: ciclo de investimentos, novos competidores e a questão do descarte de pneus inservíveis. BNDES Setorial. Rio de Janeiro, n. 25, p. 107-130, mar. 2007.

INSTITUTO BRASILEIRO DE GEOGRAFIA E ESTATÍSTICA - IBGE. Nota técnica Estimativas da população dos municípios brasileiros. Brasília, 2014. Disponível em: $<$ http://www.ibge.gov.br>. Acesso em: 16 de jul. 2015.

LAGARINHOS, C. A. F. Reciclagem de pneu: Análise do impacto da legislação ambiental através da logística reversa. 2011. 293 f. Dissertação (Doutorado em Engenharia) - Escola Politécnica da universidade de São Paulo, São Paulo, 2011.

LAGARINHOS, C. A. F.; TENÓRIO, J..A. S.. Reciclagem de pneus: discussão do impacto da política brasileira. Engevista, São Paulo, v. 11, n. 1, p. 32-49, jul. 2009. 
LAGARINHOS, C. A. F.; TENÓRIO, J. A. Soares. Tecnologias Utilizadas para a Reutilização, Reciclagem e Valorização Energética de Pneus no Brasil. Polímeros: Ciência e Tecnologia, São Paulo, v. 18, n 2, p. 106-118, 2008.

LAKATOS, E. M; MARCONI, M. .A. Metodologia científica: ciência e conhecimento científico, métodos científicos, teoria, hipóteses e variáveis. .São Paulo: Atlas, 1992.

LARUCCIA, M. M.. Sustentabilidade e impactos ambientais da construção civil. ENIAC Pesquisa, Guarulhos, v. 3, n. 1, p. 70-85, jan. 2014.

MATTIOLI, L. M.L.; MONTEIRO, M. A.; FERREIRA, R.H.; PENIDO, R. C. S.. Fundação Estadual do Meio Ambiente (MG); Programa Minas Sem Lixões. Plano de gerenciamento integrado de resíduos pneumáticos - PGIRPN. Belo Horizonte: FEAM: Programa Minas Sem Lixões, 2009. .

PARRA, C. V.; NASCIMENTO, A. P. B..; FERREIRA, M. L.. Reutilização e reciclagem de pneus, e os problemas causados por sua destinação incorreta. In: ENCONTRO LATINO AMERICANO DE PÓS-GRADUAÇÃO, 10., 2010, Barra Funda. Anais... Barra Funda: Universidade Nove de Julho, 2010.

RAMOS, L. S. N. F.. A logística reversa de pneus inservíveis: o problema da localização dos pontos de coleta. 2005. 99 f. Dissertação (Mestrado em Engenharia de Produção) Universidade Federal de Santa Catarina, Florianópolis, 2005.

SCAGLIUSE, S. R.. Reciclagem de pneus inservíveis: Alternativa sustentável à preservação do meio ambiente. São Paulo. 2011. 155 f. Tese (Doutorado em Ciências e Tecnologia Nuclear) - Universidade de São Paulo. São Paulo, 2011.

SILVA, V. J. Menezes .; PACHECO, E. B. A.Vasques. Degradação Térmica de pneus inservíveis. Niterói:Jornal de plásticos,14, 20 abr. 2004.

SOUZA, M. Maciel; L., OLIVEIRA, A.M. ; PAULA, L. M. A.. M.; SIENA, O.. Logística reversa das garrafas de Skol litrão em Porto Velho-RO. Guarulhos ENIAC Pesquisa, Guarulhos, v. 3, n. 1, p. 104-121, jan. 2014. 